\title{
Discard ban: a simulation-based approach combining hierarchical Bayesian and food web spatial models
}

Maria Grazia Pennino ${ }^{1,2,3}$, Ana Helena Bevilacqua ${ }^{2}$, M. Angeles Torres ${ }^{4}$, Jose M. Bellido ${ }^{5}$, Jordi Sole $^{6}$, Jeroen Steenbeek ${ }^{6,7}$, Marta Coll ${ }^{6,7}$

1 Instituto Español de Oceanografía (IEO), Centro Oceanográfico de Vigo, Subida a Radio Faro 50-52, 36390 Vigo, Pontevedra, Spain.

${ }^{2}$ Fishing Ecology, Management and Economics, Universidade Federal do Rio Grande do Norte (UFRN), Campus Universitário s/n, 59.098-970, Natal, Brasil.

${ }^{3}$ Statistical Modeling Ecology Group (SMEG). Departament d'Estadística i Investigació Operativa, Universitat de València. C/Dr. Moliner 50, Burjassot. 46100 Valencia, Spain.

${ }^{4}$ Instituto Español de Oceanografía (IEO), Centro Oceanográfico de Cádiz, Puerto Pesquero, Muelle de Levante s/n, 11106 Cádiz, Spain.

${ }^{5}$ Instituto Español de Oceanografía (IEO), Centro Oceanográfico de Murcia, Calle Varadero 1, Apdo. 22, 30740 San Pedro del Pinatar, Murcia, España.

${ }^{6}$ Institut de Ciències del Mar (CMIMA-CSIC), P. Marítim de la Barceloneta, 37-49, 08003 Barcelona, Spain.

${ }^{7}$ Ecopath International Initiative Research Association, Barcelona, Spain.

\begin{abstract}
Discarding is one of the most important topics in fisheries management, both for economic and ecological reasons. The European Union has included, through the current EU Common Fisheries Policy (CFP) Regulation, a discard ban with a quite controversial instrument: to enforce the landing of unwanted catch as a measure to promote their reduction. This management decision may condition the future of the fishing exploitation in European Sea. Within this context, both stakeholders and policy makers are now claiming for more effective tools that can be used to support the decision-making framework. In this study, we propose a simulation-based approach combining hierarchical Bayesian Spatial Models (H-BSMs) with the spatial-temporal module of Ecopath with Ecosim (EwE) approach, Ecospace, in the North Western Mediterranean Sea. In particular, we firstly assessed high-density discard areas using H-BSMs with fisheries and environmental data, and secondly, we simulated potential management options to identify the tradeoffs of the discard ban application within these areas using EwE. We argue that coupling novel methods, as the ones used in this study, could be a decisive step to identify the best management action among a set of different scenarios within the context of the discard ban application in European Seas.
\end{abstract}

Keywords: Bayesian model, discards, Ecospace, food web model, landing obligation, Mediterranean Sea, spatial ecology. 


\section{Introduction}

47 Worldwide discarding is one of the most important issues in fisheries management as it has negative

48 impacts on ecosystems, the economy, and society [1,2]. Indeed, discards represent a wasteful use of

49 resources and, consequently, generate future economic losses for fisheries, populations,

50 communities and ecosystems [3].

51 There is an increasing effort to understand the complex array of factors that influence the discard

52 process [4:6] and to assess the spatial-temporal dynamics surrounding this process [7:10].

53 Within the European Union (EU hereafter) waters, a number of factors are responsible for the high

54 level of discards, including the use of non-selective fishing gear, lack of market value for certain

55 species, minimum landing size restrictions, and the overlap between fishing grounds and species

56 home range [11]. One of the most important recent changes regarding discard management is the

57 shift in focus to what is caught rather than what is landed [12, 13]. The European Common

58 Fisheries Policy (CPF) introduced a 'discard ban' measure between January 1, 2015 to the January

59 1, 2019 for all regulated species in EU waters (Article 15, EU Regulation 1380/2013), which

60 determined that all catches of regulated commercial species be landed and counted, and compared

61 against their quota. This management strategy, should it be extended, could determine the future of

62 fishing exploitation in European seas with short-term and long-term socio-economic and ecological

63 implications. For these reasons, stakeholders and policy makers alike now demand more effective

64 tools to support the decision-making framework.

65 To explore alternative management options and to identify the ecological trade-offs of the discard

66 ban, a simulation-based approach that couples species distribution models, specifically the

67 hierarchical Bayesian Spatial Models (H-BSMs), with ecosystem models, using the food-web

68 model Ecopath with Ecosim (EwE), might offer an innovative approach. H-BSMs are particularly

69 appropriate to identify discard hotspots as they can explicitly model the spatio-temporal variability

70 of discards [14]. When geo-referenced discard data are analyzed, it is common to include 
71 geographic coordinates (latitude and/or longitude) in the models as continuous explicative variables

$72[15,16]$, given that fixed effects and, therefore, the spatial dependency of observations is not

73 considered. Similarly, a non-random spatial variable [17] or geographic fishing boundaries [18] can

74 be included as predictors in models to try to capture spatial discard trends [7]. However, only

75 geostatistical techniques intrinsically incorporate a component to account for spatial autocorrelation

$76[19,20]$. H-BSMs extend the concept of spatial autocorrelation in multilevel structures, including a

77 spatial random effect that is a stochastic process indexed in space, which represents all spatially

78 explicit processes that may influence the discard pattern. By applying H-BSMs to discard data the

79 multiple sources of uncertainty associated with both the observed data and the discard process can

80 be included in the analysis to generate a more robust statistical inference. Moreover, H-BSMs is not

81 only better able to identify discard hotspots, but also predict them and, therefore, contribute to better

82 spatial management planning [21, 7, 8, 10, 22].

83 Ecological processes and human activities, in addition to environmental factors, can indeed affect

84 the discard phenomena and need to be explicitly considered in process-based oriented modelling,

85 such as Ecopath with Ecosim food-web modelling (EwE) [23]. EwE is an ecosystem modelling

86 approach that builds food-web models by describing the ecosystem through energy flows between

87 functional groups with similar functional and ecological traits. Within EwE, Ecospace is a spatial-

88 temporal dynamic module that represents temporal and spatial $2 \mathrm{D}$ dynamics of trophic web

89 components $[24,25]$. This approach has been widely used to quantify the spatial impact of fisheries

90 on marine species [26], to analyse the impact of management scenarios such as the establishment of

91 marine protected areas [27], to develop spatial optimization routines [28], and to assess the impact

92 of climate change on marine ecosystems [29, 30]. EwE has also been used to model the ecological

93 impacts of changes in fishing gear, for example to measure the ecological consequences of reducing

94 discarding from bottom trawling in the NW Mediterranean Sea [31]. Recently a new Ecospace

95 module has been implemented that integrates niche modelling into the food web modelling 
96 approach [32: 36]. This new tool, combined with the spatial-temporal framework module of EwE

97 [30], bridges the gap between envelope environmental models and food web models [32].

98 In this study, we apply Bayesian spatial modelling with ecological modelling techniques to analyze

99 fishery discard and environmental data in the Southern Catalan Sea ecosystem. First, the Bayesian

100 approach is used to model the amount and distribution of discards in the study area. Next, we use

101 the EwE approach to evaluate the ecological consequences of discards on commercial and non-

102 commercial species under different degrees of the discard ban by examining a broad number of

103 ecological indicators related to trophic network dynamics. Finally, we reflect on how the

104 simulation-based coupling framework tested here can provide a new and useful tool to explore

105 management strategies that benefit fishers and possibly improve economic revenues while reducing

106 the ecological impacts and pressure on non-target species.

107

108 Material and Methods

109 Study area

110 The study was carried out in the Southern Catalan Sea (Figure 1), an area of relatively high

111 productivity due to a joint effect of the Northern current and the run-off of the Ebro and Rhone

112 rivers $[37,38]$. The continental shelf in this area is narrow, with the northern current flowing south-

113 westwards along the continental slope toward the wider continental shelf surrounding the Ebro

114 Delta River. This area is an important fishing ground for both small pelagic and demersal species

$115[39,40]$, as well as at risk predatory marine species, such as marine mammals and seabirds [41]. 


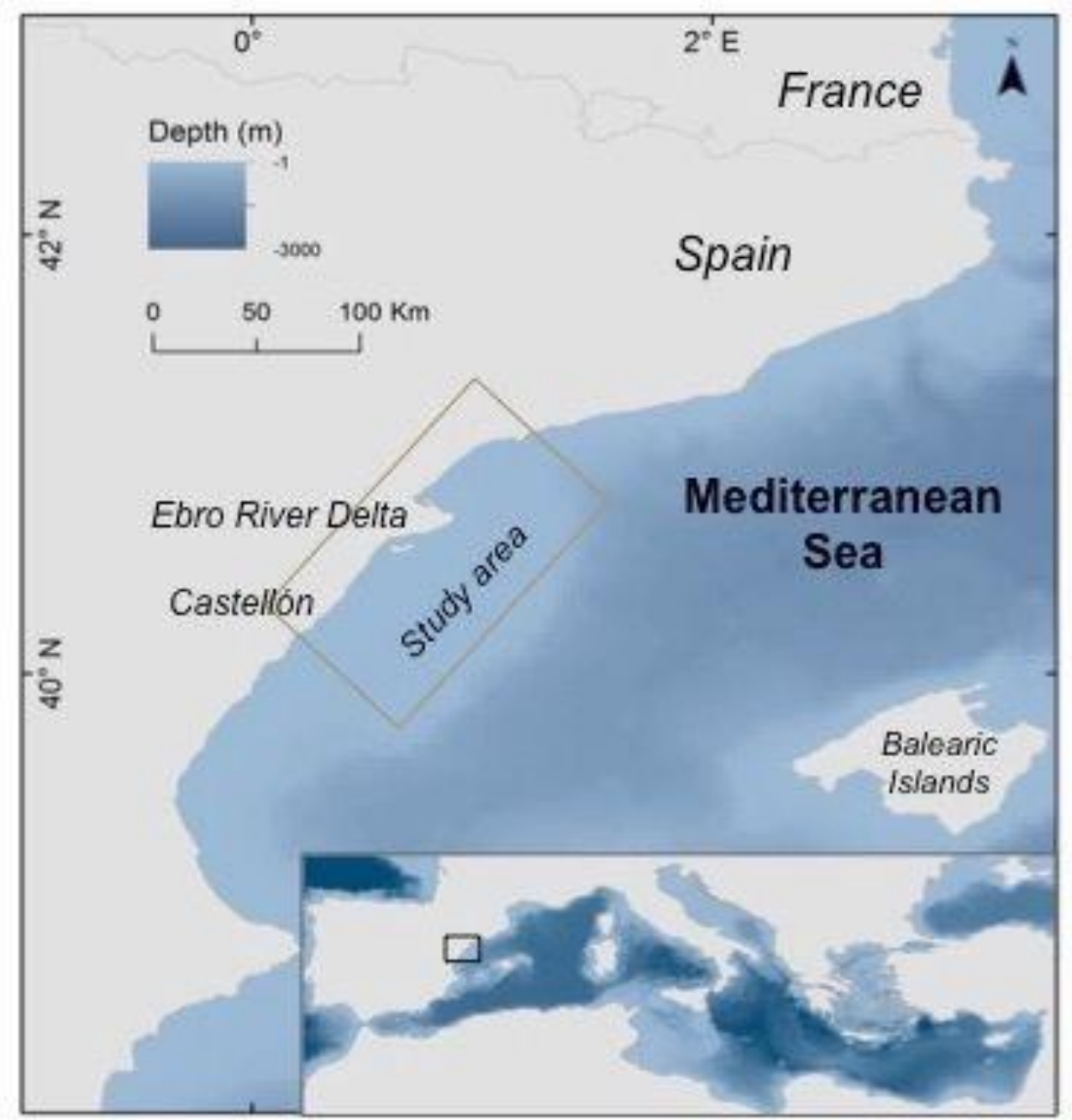

117 Figure 1: Study area located in the North-western Mediterranean Sea.

119 Discards, landings and fishing effort datasets

120 Catch and discards data from 2009 to 2016 were collected by the Instituto Español de Oceanografía

121 (IEO, Spanish Oceanographic Institute), under the EU Data Collection Framework (EC Regulation 122 199/2008) [42]. A métier approach was used in the sampling design, which is a method that

123 formally segments fisheries by vessel type, gear, fishing grounds and target species [8]. On-board

124 observers collected monthly discards data for each sampled haul as estimation between landings

125 and the total catch. The reference fleet for this study was the bottom otter trawl fleet that operates in

126 the Southern Catalan Sea (Geographical Sub Area 06 North), which targets a mixed species métier

127 (hereafter OTB-MIX). The OTB-MIX includes trawlers that usually operate in the continental shelf 
128 waters (from 50 to $200 \mathrm{~m}$ depth) with different target species. European hake (Merluccius

129 merluccius), red mullet (Mullus barbatus), Norway lobster (Nephrops norvegicus), and octopus

130 (Octopus vulgaris), are the most common species. These trawlers make short hauls of about 2-4

131 hours with about 2-3 fishing hauls per trip and land in Castellón and Tarragona harbours, the two

132 main fishing ports in the study area.

133 Since the catch and discard statistics varied markedly among vessels, catch per unit effort (CPUE)

134 and discards per unit effort (DPUE) were calculated by the catch and discard weight per haul

135 duration $(\mathrm{kg} / \mathrm{h})$. Two CPUE variables were calculated: one of the total discards (hereafter CPUE tot $_{\text {) }}$,

136 and the other of the regulated species (hereafter $\mathrm{CPUE}_{\text {reg }}$ ) defined in Annex III of Regulation (EC)

137 No 1967/2006 (see Appendix 1 for the specific regulated species). Similarly, two DPUE response

138 variables were created: one representing total discards in order to assess the overall ecological

139 impact of the fishery (hereafter $\mathrm{DPUE}_{\mathrm{tot}}$ ), and the other representing the discards of regulated

140 species, which have a minimum landing size (hereafter DPUE $\mathrm{reg}_{\mathrm{rg}}$ ). Finally, all DPUE measures were

141 log-transformed to down weight extreme values, to achieve normality and ensure a better fit of the

142 models (Shapiro and Kolmogorov-Smirnov tests, p-values < 0.05). Landing datasets collected in the

143 fishery harbours located in the studied area where the OTB-MIX métier land were provided by the

144 General Secretariat of Fisheries of the Spanish Ministry of Agriculture, Food and Environment 145 (MAPAMA).

\section{Environmental data}

148 To predict DPUE we included both oceanographic variables (i.e., Sea Surface Temperature (SST), 149 Sea Bottom Temperature (SBT), Sea Surface Salinity (SSS), Sea Bottom Salinity (SBS), Primary 150 Production (PP)) and physical descriptors (i.e., bathymetry and type of the seabed) as possible 151 predictors in the models (Table 1).

152 Oceanographic variables were derived for the entire study area from a regional application of the 
153 ROMS model [43] which is coupled with a biogeochemical nitrogen-based plankton model [44]

154 already tested for spatial applications in the Mediterranean Sea $[45,33,36]$. Implementation of the

155 ROMS was adapted to the Catalan Sea with a grid of $2 \times 2 \mathrm{~km}$ resolution and a vertical resolution of

15640 levels. Climatologies were used as boundary conditions and were derived from the NEMO

157 model (available from http://www.nemo-ocean.eu) [46], following the same procedure used in Coll

158 et al., [47]. Bathymetry and the types of seabed were obtained from the European Marine

159 Observation Data Network (EMODnet Bathymetry Consortium (2018): EMODnet Digital

160 Bathymetry (DTM), http://doi.org/10.12770/18ff0d48-b203-4a65-94a9-5fd8b0ec35f6).

161 Specific values for the environmental variables In each fishing location were extracted using the

162 "extract" function of the "raster" package [48] in the R software [49].

163 Both physical and oceanographic variables were explored for correlation, collinearity, outliers, and

164 missing data before they were included in the model. Correlation among variables was checked by

165 performing a Spearman's correlation test with the "cor.test" function of the R software. Collinearity

166 was tested by computing the generalized variance-inflation factors (GVIF), which are the corrected

167 VIF values by the number of degrees of freedom of a predictor variable [50]. The GVIF was

168 assessed using the "corvif" function in R software. All variables used in the models have a GVIF

169 lower than 3 and a Spearman's correlation lower than 0.70 ( $\mathrm{p}$-value $>0.05$ ). Outliers and missing

170 data were checked using the procedure elaborated by Zuur et al. [51].

171 Environmental predictors, as well as the computed CPUEs measures, were standardized (difference

172 from the mean divided by the corresponding standard deviation) to facilitate visualization and 173 interpretation.

\section{Modelling high density DPUE areas}

176 Hierarchical Bayesian spatial models (H-BSMs) were used to identify the high-density DPUE areas

177 for both total discards and discard of regulated species. Specifically, the expected values of DPUE 
178 in each haul ( $\mu$ DPUE) were related to the spatial, temporal and environmental covariates according

179 to the general formulation,

$$
\mu D P U E_{i j k}=X_{i j}+Y_{j}+W_{i}+Z_{k}
$$

181 where $\beta$ represents the vector of the regression coefficients, $X_{i j}$ is the vector of explanatory covariates listed in Table 1 at year $j$ and location $i, \mathrm{Y}_{\mathrm{j}}$ is the component of the temporal unstructured random effect in year $t_{j}, \mathrm{~W}_{\mathrm{i}}$ represents the spatially structured random effect at location $i$, and $\mathrm{Z}_{\mathrm{k}}$ is the random effect of the vessel. The remaining potential source of DPUE variability could be due to differences among vessels caused by a skipper effect or unobserved gear characteristics. To remove bias caused by vessel-specific differences in fishing operation, we included a vessel effect. In addition to the environmental variables, CPUE measures $\left(\mathrm{CPUE}_{\mathrm{tot}}\right.$ and $\left.\mathrm{CPUE}_{\mathrm{reg}}\right)$ for each fishing haul were included as possible predictors of DPUE variability, as well as a month factor to assess intra-annual variations.

H-BSMs were fitted using the Integrated Nested Laplace Approximation (INLA) package [52] in the R environment. INLA performs Stochastic Partial Differential Equations (SPDE) [53] for the spatially structured random effect, which approximates a continuously indexed Gaussian Field (GF) with a Matérn covariance function by a Gaussian Markov Random Field (GMRF). The spatial effect is a numeric vector that links each observation to a spatial location and, thus it accounts for independent region-specific noise that cannot be explained by the available covariates [54]. This component is defined in terms of two hyperparameters, $\kappa$ and $\tau$, that are related to the range and scale of the spatial effect [55]. A multivariate Gaussian distribution with a mean of zero and a

198 Matérn spatially-structured covariance matrix were assumed for the spatial component (see [54] for 199 more information about how to express prior knowledge of spatial effects).

200 A vague Gamma prior distribution with shape and scale parameters of 1 and 5e-05, respectively, 201 was assumed for the precision parameter $\gamma$ of the temporal component. Vague prior distributions 
202 with a zero-mean and a standard deviation of 100 were used for all the fixed effects since no prior

203 information was available.

204 Model selection was performed by testing all possible combinations among the non correlated

205 variables considering the Watanabe Akaike Information Criterion (WAIC) [56] for goodness of fit 206 and the Log-Conditional Predictive Ordinates (LCPO) [57] for predictive quality measures.

208 Ecopath with Ecosim modelling approach

209 The basic routine of Ecopath is to provide a snapshot of the structure and flows of a food web and 210 describe the balance between production of functional groups and consumption within an 211 ecosystem. Each functional group can represent a species, a sub-group of a species (e.g., juveniles 212 and adults) or a group of species with functional and ecological similarities. Ecopath is the starting 213 point to develop temporal and spatial-temporal modelling approaches using Ecosim and Ecospace 214 [22]. A description of the EwE methodology, main applications and limitations can be found in the 215 literature $[23,58,59,60]$.

216 The Ecopath model uses a system of linear equations to describe the average flows of mass and 217 energy between these groups during a specific period of time, (normally a year). The flow to and 218 from each group is described by the following equation:

$$
B_{i} \cdot(P / B)_{i}=\sum B_{j} \cdot(Q / B)_{j} \cdot D C_{i j}+Y_{i}+E_{i}+B A_{i}+B_{i} \cdot(P / B)_{i} \cdot\left(1-E E_{i}\right)
$$

220 where $B_{i}$ is the biomass of group $i,(P / B)_{i}$ is the production per unit of biomass, $Y_{i}$ is the total fishery 221 catch rate, $E_{i}$ is the net migration rate (emigration-immigration), $B A_{i}$ is the biomass accumulation 222 rate, $E E_{i}$ is the ecotrophic efficiency, which is defined by the proportion of production that is 223 utilized in the system, $B_{j}$ is the biomass of consumers or predators $j,(Q / B)_{j}$ is the consumption per 224 unit of biomass $j$, and $D C_{i j}$ is the fraction of $i$ in the diet of $j$.

225 For each functional group $i$, at least three of the four basic parameters are required: biomass $\left(B_{i}\right)$, 
consumption rates $(Q / B)_{i}$ and production rates $(P / B)_{i}$, and ecotrophic efficiency $\left(E E_{i}\right)$. The fourth parameter is estimated in the model [23]. Diet composition $\left(D C_{i j}\right)$ and fishing yields and other exports $\left(Y_{i}\right.$ and $\left.E_{i}\right)$ are also needed.

Ecosim is a temporal dynamic module that is able to simulate ecosystem effects of (mainly fishing) mortality changes and environmental forcing over time $[23,24,25]$. The model uses a system of time-dependent differential equations from the baseline mass-balance model (see Eq. 3), where the biomass growth rate is calculated as:

$$
d B_{i} / d t=g_{i} \cdot \sum Q_{j i}-\sum Q_{i j}+I_{i}-\left(M_{i}+F_{i}+e_{i}\right) \cdot B_{i}
$$

where $d B_{i} / d t$ represents the biomass growth rate of group $i$ during the time interval $d t, g_{i}$ is the net growth efficiency (production/consumption ratio, $P / Q$ ), $M_{i}$ is the natural mortality rate $\left((P / B)_{i} \cdot B_{i}\left(1-E E_{i}\right)\right), F_{i}$ is the fishing mortality rate, $I_{i}$ is immigration rate, and $e_{i}$ is emigration rate. The two sums from equation 3 estimate consumption rates. The first expresses total consumption by group $i$, and the second predation by all predators in the same group $i$. The consumption rates, $Q$, are calculated based on the 'foraging arena' concept, where $B_{i}$ 's are divided into vulnerable and non-vulnerable components [61].

The set of Ecosim equations are used in the spatial routine Ecospace, the spatial-temporal model of $E w E$, which predicts the biomass dynamics in a two-dimensional space [24]. 'Water' cells in Ecospace can be assigned to contain one or more habitat types and species can be assigned preferred habitats [23]. Fishing fleets can be limited to fish in specific habitats and can be subjected to zonal fishing regulations (no take zones) [24]. The model further incorporates organism dispersal rates and other behavioural parameters [23].

In this study, the ecosystem model of the Southern Catalan Sea that was developed with Ecopath with Ecosim (EwE) $[62,63,64]$ was run to analyze the spatial-temporal dynamics of marine resources and the ecosystem under different discard ban policy scenarios. This model, previously 
250 fitted to 1978- 2010 time series [65] includes 40 functional groups and four fishing fleets (bottom

251 trawling, purse seining, long lining and tuna fishing), and covers an area of 5,000 $\mathrm{km}^{2}$ with depths

252 from 50 to $400 \mathrm{~m}$ [66]. A previous Ecospace model, which was developed to evaluate the combined

253 effects of environmental conditions and fishing in the ecosystem dynamics of the Southern Catalan

254 Sea, was used as a starting point with the original configuration as the default setting [66]. The

255 environmental variables used to parameterize the Ecospace model were the same as those used for

256 the H-BSMs. The primary production spatial pattern was used to drive the dynamics of the

257 phytoplankton group (through the variation of the initial P/B value) of the food web model [64].

\section{Ecosystem simulations and analyses}

260 Starting from the original Ecosim model and previously developed Ecospace configurations [64, 65,

261 66], a series of spatial-temporal simulations were run and compared against a non-discard ban

262 scenario. Spatial-temporal simulations were developed for the period 2016 to 2020 and the model

263 was let to keep running until 2030 (Table 2). EwE version 6.6 and the spatial-temporal framework

264 module of $E w E[30]$ were used to implement the discard ban scenarios at specific points in time and 265 space.

267 A first group of simulations was carried out and ran until 2030 using an Ecosim temporal dynamic 268 model and did not include spatial information:

269 S0: Baseline simulation - the original Ecosim model fitted to time series from 1978 to 2010 was 270 used and ran to 2030 and did not include implementation of a discard ban policy.

271 S1: total implementation of the discard ban on regulated species, i.e., 100\% reduction of discards of 272 these species in the entire study area from 2016 to 2020 and run to 2030. 
273 S2: total implementation of the discard ban on all discarded species (both regulated and not

274 regulated species), i.e., $100 \%$ reduction of all discards in the entire study from 2016 to 2020 and run 275 to 2030.

276

277 In a second group of simulations, spatial-temporal scenarios were developed, which integrated the 278 H-BSMs outputs in the spatial-temporal model Ecospace [47], and reduced 100\% of discards from 2792016 to 2020 , while running to 2030 :

280 S3: total implementation of the discard ban (100\% reduction of discards) of regulated species in the 281 entire study area.

282 S4: total implementation of the discard ban for total discarded species in the entire study area.

283 S5: total implementation of the discard ban for the regulated species only in the high intensity 284 DPUE $_{\text {reg }}$ areas identified by H-BSMs.

285 S6: total implementation of the discard ban for total discarded species only in the high intensity 286 DPUE $_{\text {tot }}$ areas identified by the H-BSMs.

\section{Ecological indicators}

289 Results from scenarios were compared by using a set of selected ecological indicators that were 290 calculated for three different years: the year the discard ban policy started (2016), the year set for 291 full policy implementation (2020), and 10 years after full implementation of the ban (2030) (Table $2923)$.

293 The ecological indicators that were chosen were divided into two categories: (1) biomass and catch-

294 based indicators, such as total catch, total catch of important commercial species (such as hake, red 295 mullets, Norway lobster, anchovy, sardine, flatfish and demersal species), total biomass of exploited 296 species, total biomass of important commercial species, total invertebrates over fish biomass, total 297 demersal over pelagic biomass, predatory biomass; and (2) ecosystem and biodiversity-based 
298 indicators, such as, Kempton's Q biodiversity index, marine trophic index (MTI), Trophic level of

299 the catch (TLc) and TLco 3.25. These are all common indicators that are regularly extracted from

300 EwE modelling [64, 65, 67]. The Kempton's Q index was calculated as a relative index of biomass

301 diversity based on the Kempton's Q index developed for expressing species diversity [61]. This

302 index includes those species or functional groups with a TL $\geq 3$, so an increase in this index implies

303 an increase in the biomass of various high TLs organisms. The TLc was used to describe how the

304 fishery and ecosystem might interact because of modelled policy measures [23].

\section{Results}

A total of 201 fishing hauls were sampled in the study area over the period 2009 to 2016. Total catch and discards for that period were $49,517 \mathrm{~kg}$ and $12,720 \mathrm{~kg}$ respectively, which is equivalent to $26 \%$ of all fisheries catch during that period. Overall, the most discarded species were Scyliorhinus canicula (726.93 kg), Engraulis encrasicolus (631.78 kg) and Galeus melastomus (604.97 kg).

311 Among the regulated species, the most discarded were Engraulis encrasicolus, Sardina pilchardus 312 (356.19 kg) and Pagellus acarne (148.24 kg).

\section{Hierarchical Bayesian spatial models}

315 SSS was highly correlated to SBS $(r>0.80)$ and SST was highly correlated to SBT $(r>0.80)$.

316 Moreover, the variables SSS and SST have a Generalized Variance Inflation Factors of (GVIF)>3.

317 Given this, separate H-BSM runs were performed and each run included only one of the highly correlated variables to determine which one would explain the most discard variance.

319 For total discards, the selected predictors (based on the lowest WAIC and LCPO values) were $320 \mathrm{CPUE}_{\text {tot }}$, month, SBT, PP and the vessel random effect, plus a stochastic spatial component that accounts for the residual spatial autocorrelation. No relevant inter-annual differences were found in 
323 higher WAIC and LCPO values that those lacking.

324 The findings showed a positive relationship between $\mathrm{CPUE}_{\text {tot }}$ and DPUE $\mathrm{tot}_{\text {to }}$ (posterior mean=1.65;

$32595 \% \mathrm{CI}=[0.96 ; 1.84])$. Conversely, both SBT and PP presented negative relationships with DPUE $\mathrm{tot}_{\mathrm{tot}}$

326 variability (posterior mean $=-0.65 ; 95 \% \mathrm{CI}=[-0.33 ;-0.10]$; posterior mean $=-1.15 ; 95 \% \mathrm{CI}=[-1.19$;

$327-0.53]$, respectively). Thus, higher values of DPUE $_{\text {tot }}$ were found in colder waters with lower

328 concentrations of PP. The months with higher estimated coefficients than the reference level

329 (January) were February and May (posterior mean $=1.23 ; 95 \% \mathrm{CI}=[0.41 ; 1.92]$; posterior mean=

$3301.05 ; 95 \% \mathrm{CI}=[0.34 ; 1.52]$, respectively). By contrast, September was found to be the month with

331 the lowest DPUE tot values.

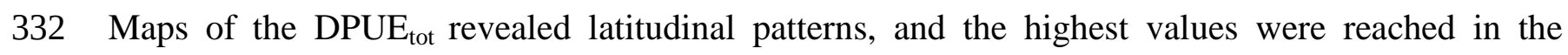

333 southern part of the study area (Figure 2) where the continental shelf is wider. The spatial

334 component effect was consistent and revealed a similar pattern (Figure 3). 

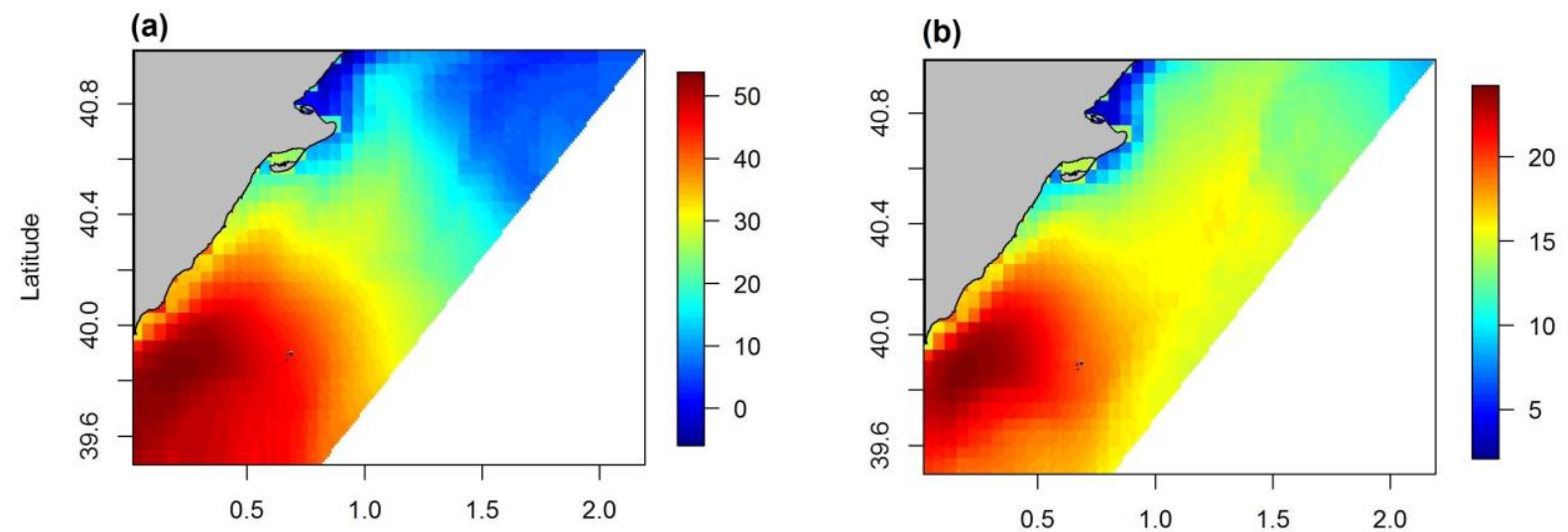

(c)
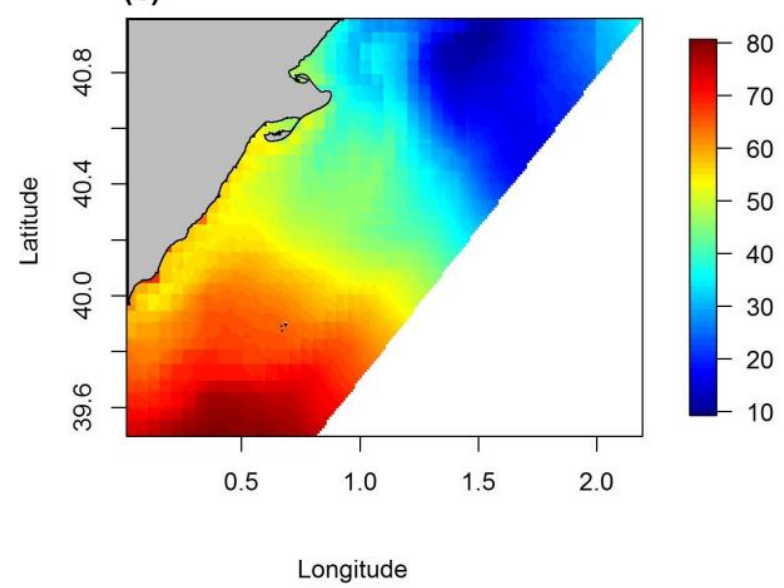

(d)

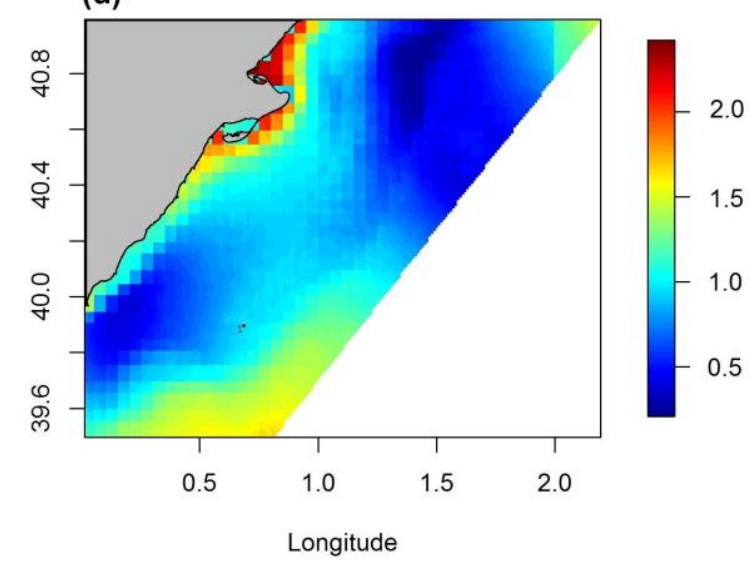

335

336 Figure 2: Posterior predictive distribution of the DPUE tot $_{\text {: }}$ mean (a); $95 \%$ credible intervals with 337 the first $(b)$ and third $(c)$ quantiles and the standard deviation $(d)$. 

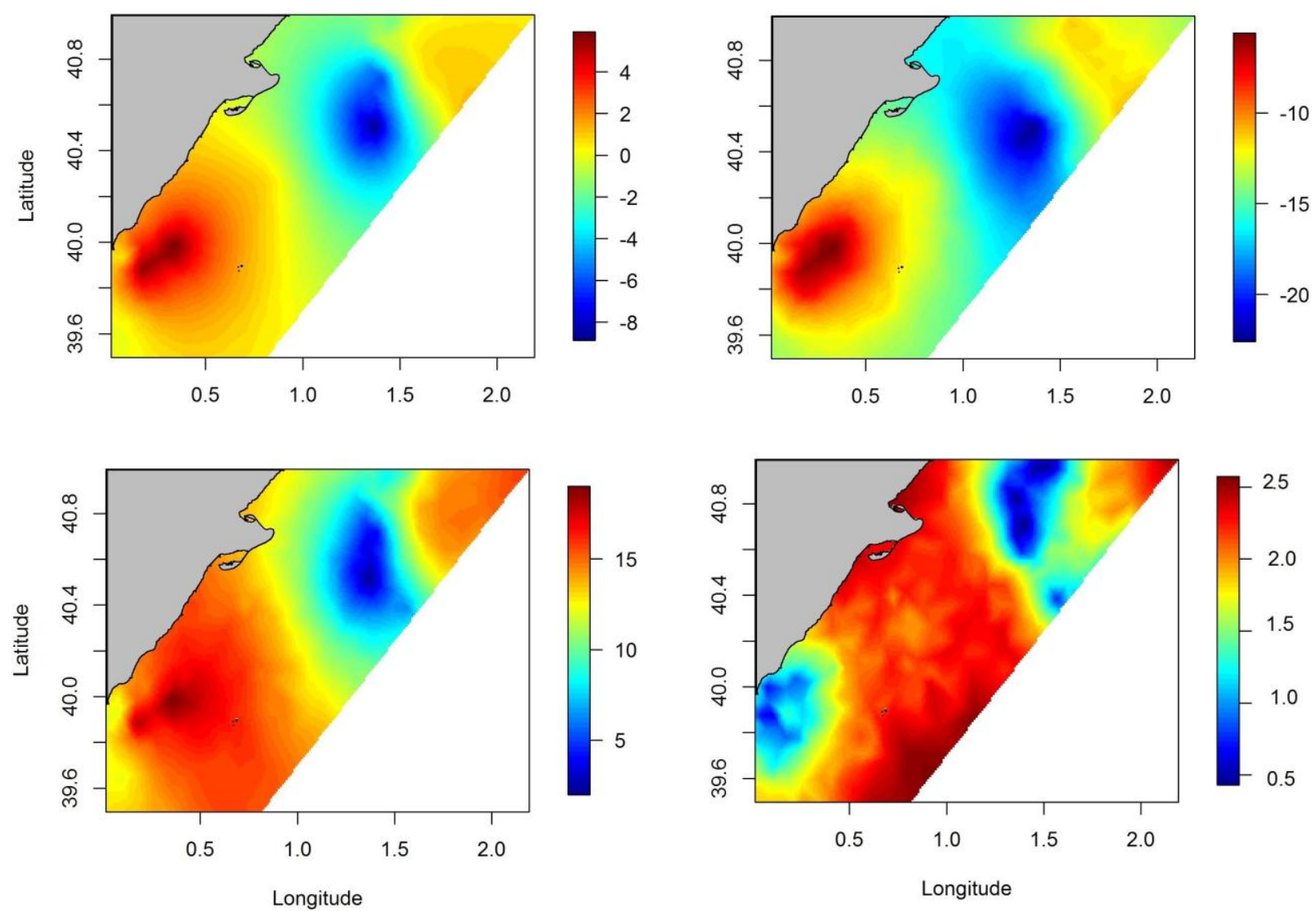

340 Figure 3: Posterior distribution of the spatial effect of the DPUE tot: mean (a); 95\% credible 341 intervals with the first (b) and third (c) quantiles and the standard deviation $(d)$.

343 With respect to DPUE $\mathrm{reg}_{\text {, }}$, the relevant covariates for the best model were CPUE $\mathrm{E}_{\text {reg }}$ bathymetry and 344 PP together with the vessel and spatial random effects. As for the DPUE $\mathrm{tot}_{\text {, }}$ no inter-annual 345 variability was identified for the $\mathrm{DPUE}_{\mathrm{reg}}$. Moreover, no monthly variation was found for DPUreg. A 346 positive relationship was found between $\mathrm{DPUE}_{\text {reg }}$ and the bathymetry, (posterior mean $=1.42 ; 95 \%$ $347 \mathrm{CI}=[0.74 ; 2.01])$, and between $\mathrm{DPUE}_{\mathrm{reg}}$ and $\mathrm{CPUE}_{\mathrm{reg}}($ posterior mean $=1.84 ; 95 \% \mathrm{CI}=[1.02$;

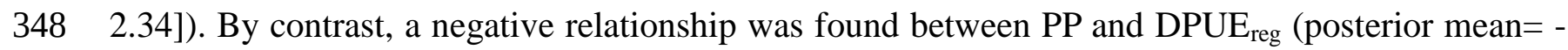
$3490.49 ; 95 \% \mathrm{CI}=[-0.53 ;-0.09])$.

350 Both the predictive spatial DPUE $E_{\text {reg }}$ values map and the posterior mean of the spatial effect map 351 (Figures 4 and 5) demonstrated that the southern part of the study area has the highest DPUE ${ }_{\text {reg }}$ 352 concentrations. A specific marked hotspot with higher DPUE $_{\text {reg }}$ was identified in waters located off 
353 Castellón.

354
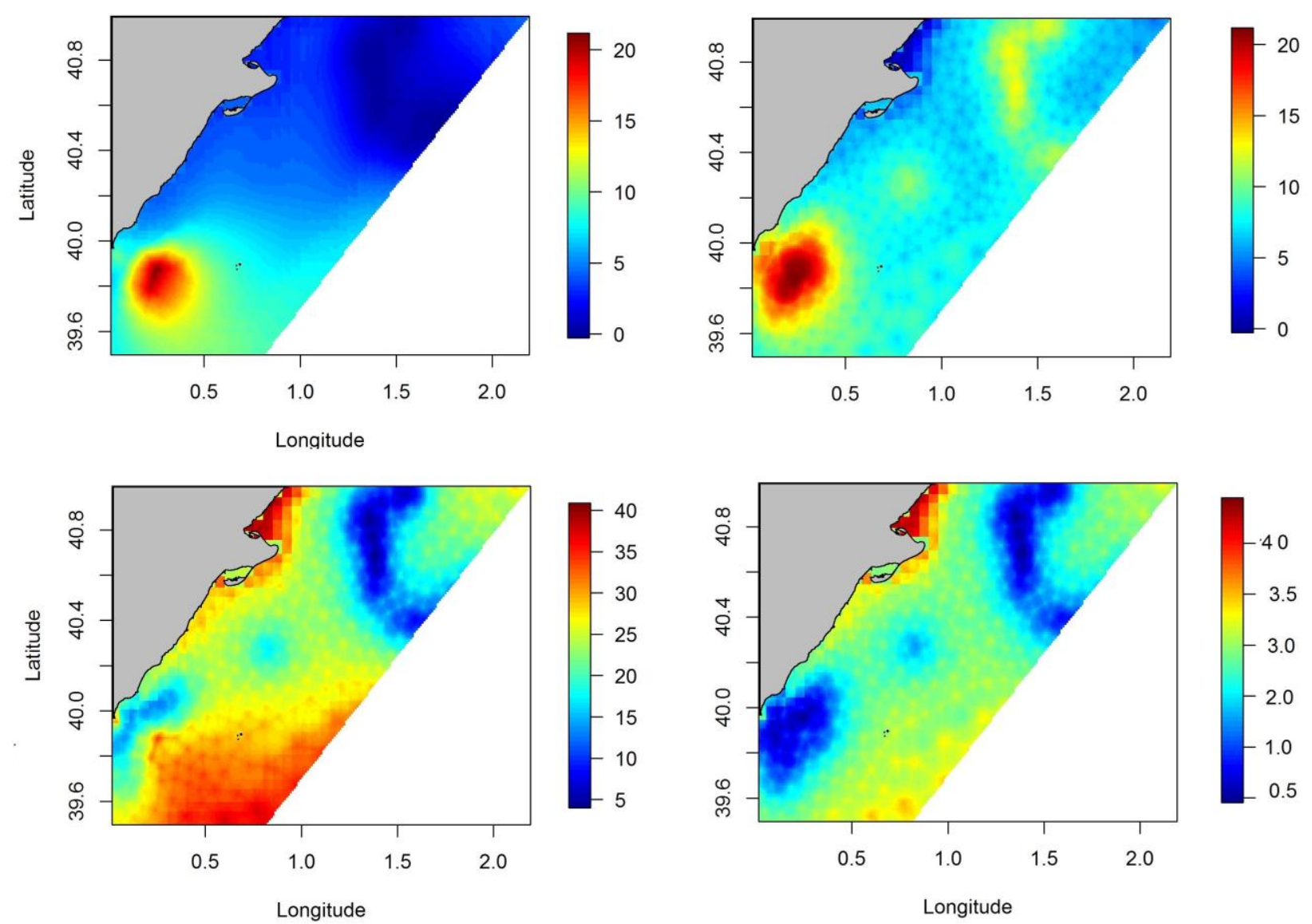

355

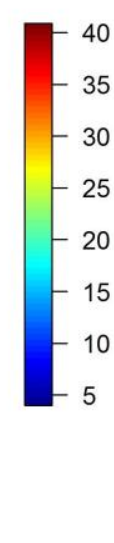

356 Figure 4: Posterior predictive distribution of the DPUE reg: mean (a); 95\% credible intervals with 357 the first $(b)$ and third $(c)$ quantiles and the standard deviation $(d)$. 

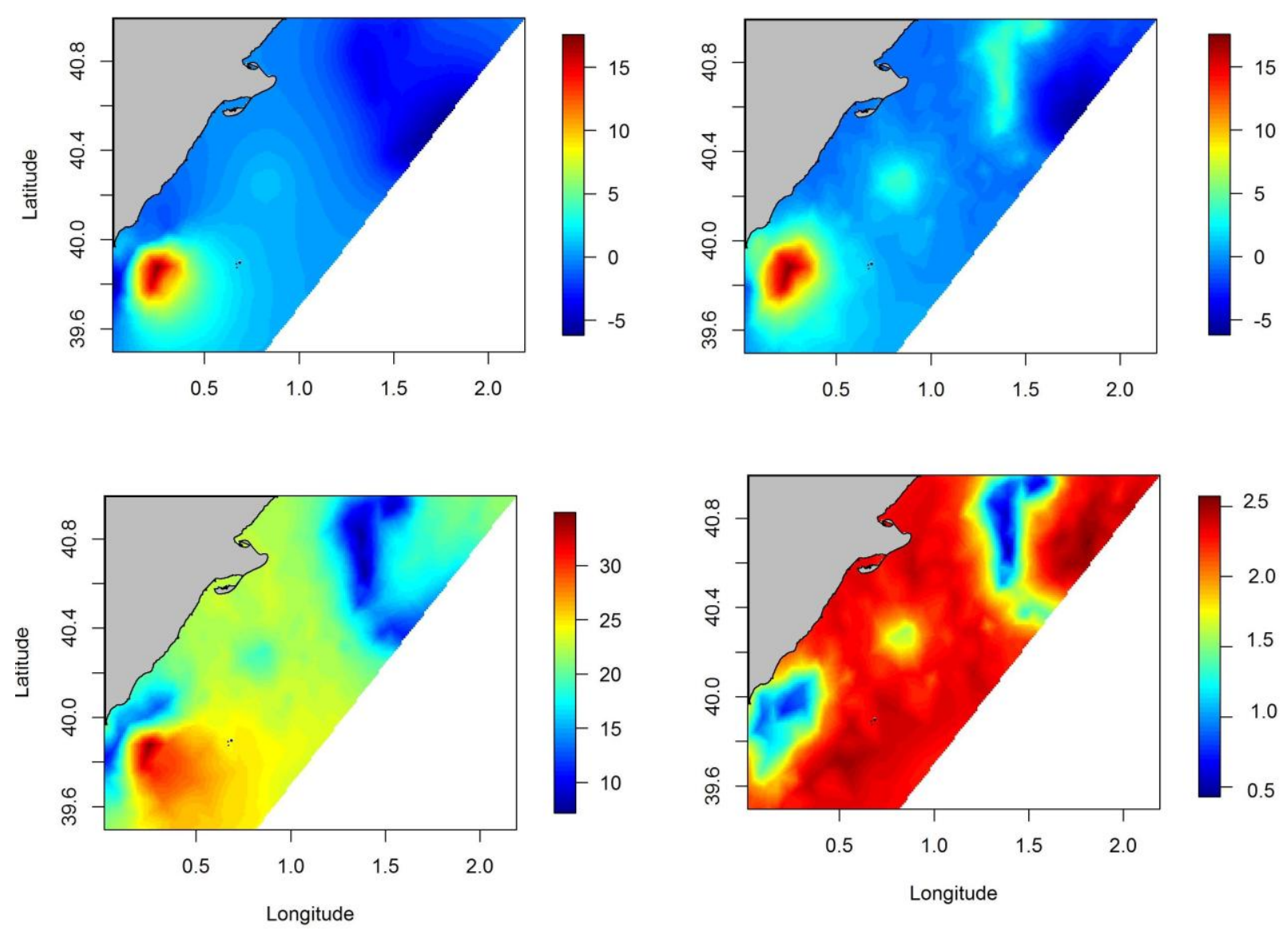

360 Figure 5: Posterior distribution of the spatial effect of the DPUE $E_{\text {reg: }}$ mean (a); 95\% credible intervals with the first $(b)$ and third (c) quantiles and the standard deviation $(d)$.

\section{Ecosystem scale simulations of the discard ban impact}

364 Compared to the baseline scenario of no discard ban, the simulations performed with the ecosystem

365 EwE model that considered regulated species predicted that the biomass and hake catch would increase, especially when submitted to spatial-temporal effects. (Table 4 and Figure 6a). These increases were higher in simulations that extended the discard ban to all discarded species, not just regulated ones. Results for Norway lobster showed that biomass increased when compared to the baseline scenario (Figure 6b), although there were no clear increases in catches. On the contrary, anchovy and sardine biomass and catches either slightly declined or increased depending on the

371 simulation. For anchovy, the discard ban on all species had a larger negative effect than it did on the 
372 discard ban for only regulated species, whereas similar results were observed for sardine in both

373 simulations of the discard ban. Result for flatfish species were contrasting. A discard ban on

374 regulated species was shown to have large positive effects, whereas a discard ban on all discarded

375 species predicted negative results, both in terms of biomass and catch (Table 4).

376 Simulations with the ecosystem EwE model predicted slight declines (mostly $<1 \%$ ) of total catch 377 and total biomass in both 2020 and 2030 under the different simulations tested in the study, when 378 compared to 2016 (Table 5). Overall, the discard ban is predicted to have moderate positive effects 379 on demersal fish catch and biomass, a slight negative impact on invertebrates (less than $1 \%$ change) 380 and a slight negative impact on total fish biomass (less than a $2 \%$ change). Changes to the total 381 invertebrates/total fish biomass were also predicted to be small, and results were contrasting: 382 positive results were obtained when the discard ban was simulated on regulated species, and 383 negative results were obtained when the discard ban was simulated on all discarded species. 384 Biomass results for other predatory species contrasted between temporal simulations (which 385 revealed a notable increase in biomass) and spatial-temporal simulations (which revealed either a 386 slight increase or decline) (Table 5). The Kempton's Q index mainly revealed slight positive 387 increases in the simulation of the discard ban on retained species, but slight negative increase was 388 observed when all species were banned from discarding. A similar behaviour was observed with the 389 MTI indicator, whereas the TLc slightly increased in all simulations, including the baseline (Table $3905)$. 

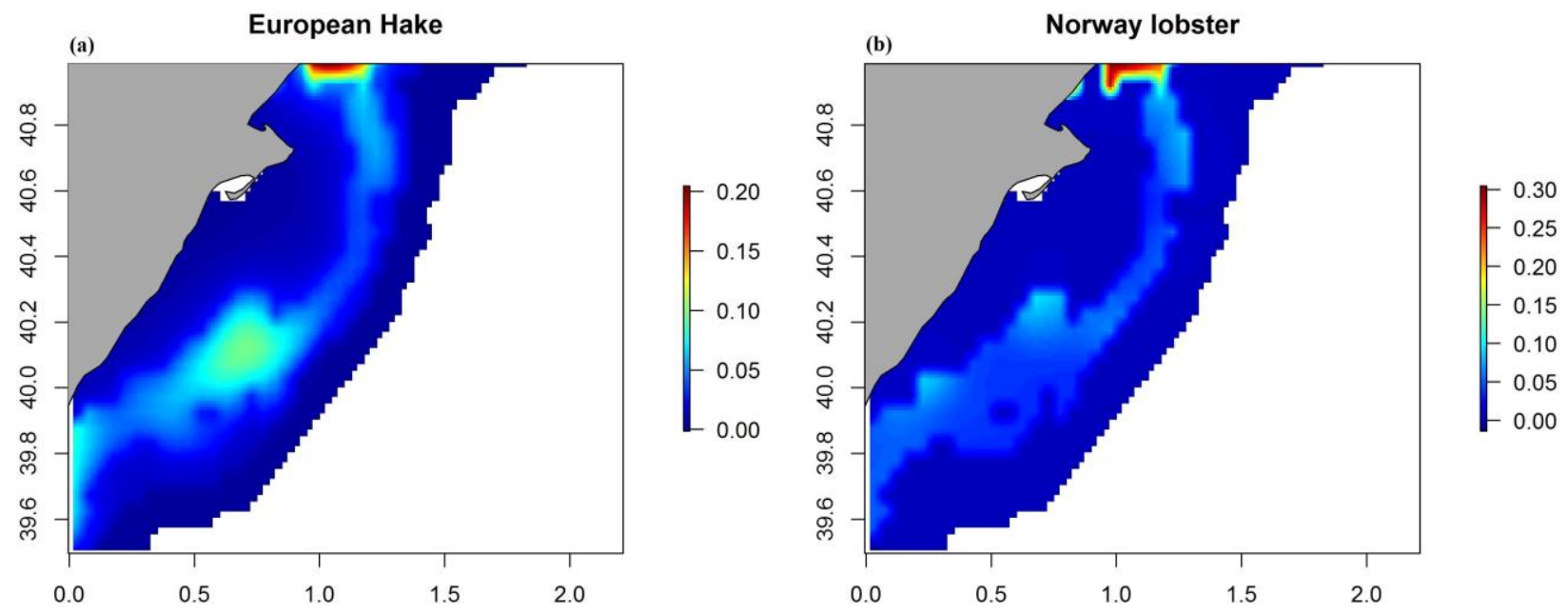

392 Figure 6: Ecospace predicted distribution of biomass $\left(\log \left(t \cdot \mathrm{km}^{-2}\right)\right)$ for European hake (a) and Norway Lobster (b) in the study area under Scenario 6 of discard banning (Table 2)

\section{Discussion}

Solving the discards problem is an urgently need to better manage fisheries. However, it is quite a complex issue given that discards vary substantially over time and space and are due to numerous factors, including environmental conditions and species composition, as well as fisheries and economic characteristics [7,8]. The new obligation to land discards in European Seas may have unpredictable and unwished ecological, socio-economic and operational impacts [2,68]. For these reasons we tested a simulation-based approach that combined H-BSMs with spatial-temporal EwE modelling to assess the potential effects of implementing the 'landing obligation' in a highly exploited ecosystem in the North Western Mediterranean Sea. Overall, we found that the amount of discard in our study area between 2009-2016 accounted for $26 \%$ of the total catch. Similar studies on demersal trawls reported higher discard ratios, such as in the north-eastern Mediterranean Sea (38-49\%) [69:71] and in the south Spain area (31-34\%) [7]. However, the discard ratio in our study and in the Adriatic Sea (up to 15\%) [73].

411 From a species composition point of view, a large portion of discard was of the elasmobranch

412 species, which are considered vulnerable species due to their biology and K-selection life-history 
413 traits [74]. Discard non-target vulnerable species may have negative consequences for both

414 commercial and non-commercial species owing to the effects on species interactions and cascading

415 effects throughout the trophic web.

416 Our findings did not identify any relevant temporal trends over the years in either DPUE measures.

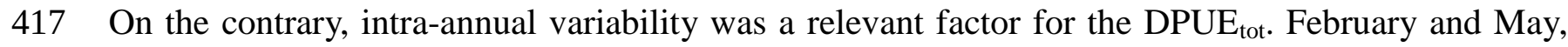
418 specifically, were the months that recorded the highest DPUE values. This could be attributed to the 419 fisher targeting behaviour during these months [75], and in general due to spatial seasonal patterns 420 of the marine community [76, 77].

421 Furthermore, discarding is a decision taken on board and based on a given fisher's discarding 422 pattern, which is influenced by different factors, such as market dynamics for a given species or 423 other legal and regulatory constraints. Indeed, for both DPUE measures, H-BSMs identified the 424 random vessel effect to be a relevant variable that could affect the discard amount. This effect 425 should collect this hidden variability that otherwise could not be analyzed.

426 Moreover, for both DPUE measures, results showed a direct and positive relationship between the 427 CPUE and the DPUE, meaning that more catches lead to more discard. This result is in line with 428 other studies that found the same relationship in other exploited areas $[6,8]$.

429 In terms of which variables could be driving the spatial distributions and discard abundance, some 430 differences were found between total discards and regulated species discards. For example, 431 bathymetry was only an important factor influencing the DPUE variability for regulated species.

432 This result is in line with other discard studies that highlighted depth-related variations of DPUE 433 quantities as this is linked to differences in species composition and in the length-frequency 434 distribution of some particular species as the Boops boops [6, 78].

435 Both total discards and regulated species discards were affected by the primary production 436 concentration (PP). Waters with lower concentrations of PP recorded higher DPUE values. 437 Similarly, the sea bottom temperature (SBT) was negatively related to the DPUE of total discards. 
438 Thus, areas with colder and less productive waters were also the areas with high discard

439 abundances. These results can potentially be explained by two different hypotheses or a

440 combination of both: 1) the "environmental hypothesis" whereby these environmental variables are

441 directly correlated to the habitat preferences of métier target species (i.e., European hake, red

442 mullet, Norway lobster), which are also favourable to the organisms that are part of the discard; 2)

443 the "effort hypothesis" whereby fishing is more intense in areas with these characteristics and where

444 the stock of target species is more abundant.

445 The spatial effect, which indicates the intrinsic spatial variability of the discards after excluding 446 explicative variables, was relevant for both DPUE measures (total species and regulated species).

447 This result could reflect the effect of other hidden factors, such as community composition or 448 biological interactions, on the total values of DPUE Maps show a clear latitudinal pattern with a 449 specific DPUE hotspot of regulated species in waters located in front of Castellón. The 450 identification of these spatial-temporal trends and in particular of the DPUE hotspots can be 451 particularly useful for spatial management of the analyzed fleet. The intra-annual/spatial effects 452 could potentially be exploited in a spatial management strategy to reduce DPUE quantities, 453 providing there are necessary economic incentives for fishers to adopt selective temporal rotation of 454 fishing grounds.

455 According to the simulations from the ecosystem modelling exercise, the ecological benefits of the 456 discard ban would be mainly positive on European hake, a vulnerable and highly exploited or 457 overexploited species $[79,80]$, and on Norway Lobster, a highly exploited invertebrate $[81,82]$ in 458 the Mediterranean Sea. These impacts would be larger if the discard ban were extended to the entire 459 list of discarded species, instead of just the regulated ones. However, other regulated species would 460 show contrasting results. Likely, due to their role as prey and competitor species, smaller species 461 that mainly play a prey role in the ecosystem may be negatively affected by the recovery of their 462 predators (such as European hake as predator and anchovy as prey) or recovery of competitors 
463 (such as demersal fish and flatfishes that can compete for similar preys). These results highlight that 464 considering inter-specific food-web dynamics are essential to identifying the ecological 465 consequences [68] and trade-offs of fisheries management and exploitation alternatives [83].

466 Ecosystem simulations also illustrated that the impact of the discard ban on the ecosystem may be 467 limited and only a slight recovery of the ecosystem structure may be achieved by a discard ban. 468 Some indicators showed a partial recovery of the ecosystem health with the implementation of the 469 discard ban, such as demersal fish biomass. However, most of them did not show clear signs of 470 recovery [67]. This can be related to the fact that the study exclusively simulated a discard ban of 471 bottom trawling and did not include other measures or fleets. Additional fleets, such as purse seiners 472 and small-scale fisheries, also have a large negative effect on marine resource and thus an 473 intervention on these fleets may be needed to recover highly exploited Mediterranean species and 474 communities, such as a reduction of fishing effort or total closure of sensitive areas (e.g., nurseries, 475 spawning areas or aggregation areas). Due to the poor situation of many exploited stocks (such as 476 European hake, European sardine and European anchovy) and ecosystems in the Mediterranean Sea 477 [80] this study highlights that more drastic measures may be needed to yield clearer results in terms 478 of recoveries of stocks and communities in Southern European Seas, in addition to a full 479 implementation of the discard ban.

480 Finally, our results highlight that the choice of modelling framework used to analyse the discard ban 481 outcomes is important because in some cases our modelling results contrasted when implementing a 482 temporal or a spatial-temporal approach. This is mainly because fishing effort, catch and discarding 483 generation show heterogeneous spatial patterns.

484 Bayesian spatial models can be a powerful approach to identifying discard hotspots given that they 485 quantify both the spatial magnitude and the different sources of uncertainty. However, these models 486 often include only implicit biotic interactions (such as competition, predation etc.) and simulation of 487 future management scenarios are not performed straightforwardly. By contrast, these options are 
488

489

490

491

492

493 494

495

496

497

498

499

500

501

502

503

504

505

available with the $E w E$ approach, which did not include an explicit spatial component to account for the spatial autocorrelation and a quantification of the uncertainty. By combining these two techniques we can gain clear advantages for the exploration of management strategies and, specifically, assess possible discard ban implementations and consequences. This approach could be extended to others case study in others European fishing areas using similar data to test similarity and possible difference in the discard ban implementation.

\section{Acknowledgments}

Data analysis of this study was funded by the Project iSEAS, Ref. LIFE13 ENV/ES/000131, “Knowledge-Based Innovative Solutions to Enhance Adding-Value Mechanisms towards Healthy and Sustainable EU Fisheries", cofounded under the LIFE+Environmental Program of the European Union. This study is a contribution to the PELWEB project (ES-PN-2017-CTM2017-88939-R, Spanish National Plan).MC and JS acknowledge financial support from the European Union`s Horizon research program grant agreement No 689518 for the MERCES project. MAT has received funding by the European Commission's Horizon 2020 Research and Innovation Programme under Grant Agreement No. 634495 for the MINOUW project. The authors are deeply grateful to all the observers who gathered the fishing data, as well as the fishers who participated in the sampling. Collection of the fishing data used in this paper was funded by the European Union through the European Maritime and Fisheries Fund (EMFF) within the National Program of collection, management and use of data in the fisheries sector and support for scientific advice regarding the Common Fisheries Policy.

\section{References}

[1] Bellido, J. M., Santos, M. B., Pennino, M. G., Valeiras, X. and Pierce, G. J. 2011. Fishery discards and bycatch: solutions for an ecosystem approach to fisheries management?. Hydrobiologia, 670(1): 317-333.

[2] Sarda, F., Coll, M., Heymans, J.J. and Stergiou, K.I. 2015. Overlooked impacts and challenges of the new European discard ban. Fish and Fisheries, 16: 175-180. 

M., Lucchetti, A., Brcic, J.,Villasante, S., Ballesteros, M.A., Chapela, R., Santiago, J.L., Agnarsson, 518 S., Og,undarson, O. and Erzini, K. 2016. The EU landing obligation and European small-scale 519 fisheries: What are the odds for success?. Marine Policy, 64: 64-71.

520 [4] Catchpole, T. L., Frid, C. L. J. and Gray, T. S. 2005. Discards in North Sea fisheries: causes, consequences and solutions. Marine Policy, 29(5): 421-430.

[5] Feekings, J., Bartolino, V., Madsen, N. and Catchpole, T. 2012. Fishery discards: factors affecting their variability within a demersal trawl fishery. PloS one, 7(4): e36409.

[6] Pennino, M. G., Vilela, R., Valeiras, J., Bellido, J. M. 2017. Discard management: A spatial multi-criteria approach. Marine Policy, 77, 144-151.

[7] Cosandey-Godin, A., Krainski, E. T., Worm, B. and Flemming, J. M. 2014. Applying Bayesian spatiotemporal models to fisheries bycatch in the Canadian Arctic. Canadian Journal of Fisheries and Aquatic Sciences, 72(2): 186-197.

[8] Pennino, M. G., Muñoz, F., Conesa, D., López-Quílez, A. and Bellido, J. M. 2014. Bayesian spatio-temporal discard model in a demersal trawl fishery. Journal of sea research, 90: 44-53.

[9] Vilela, R. and Bellido, J.M. 2015. Fishing suitability maps: helping fishermen reduce discards. Canadian Journal of Fisheries and Aquatic Sciences, 72(8): 1191-1201.

[10] Paradinas, I., Marín, M., Pennino, M. G., López-Quílez, A., Conesa, D., Barreda, D., Gonzales, M. and Bellido, J. M. 2016. Identifying the best fishing-suitable areas under the new European discard ban. ICES Journal of Marine Science, 73(10): 2479-2487.

[11] Johnsen, J. P. and Eliasen, S. 2011. Solving complex fisheries management problems: What the EU can learn from the Nordic experiences of reduction of discards. Marine Policy, 35(2): 130 139.

[12] EU Regulation (EU) No 1380/2013 of the European Parliament and of the Council of 11 December 2013 on the Common Fisheries Policy, amending Council Regulations (EC) No 1954/2003 and (EC) No 1224/2009 and repealing Council Regulations (EC) No 2371/2002 and (EC) No 639/2004 and Council Decision 2004/585/EC.

[13] Uhlmann, S.S., van Helmond, A.T.M., Stefansdottir, E.K., Sigurðardottir, S., Haralabous, J., Bellido, J.M., Carbonell, A., Catchpole, T.., Damalas, D., Fauconnet, L., Feekings, J., Garcia, T., Madsen, N., Mallold, S., Margeirsson, S., Palialexis, A., Readdy, L., Valeiras, J., Vassilopoulou, V. and Rochet, M.-J. 2014. Discarded fish in European waters: general patterns and contrasts. ICES Journal of Marine Science, 71(5): 1235-1245.

[14] Viana, M., Jackson, A. L., Graham, N., and Parnell, A. C. 2013. Disentangling spatio-temporal processes in a hierarchical system: a case study in fisheries discards. Ecography, 36(5): 569-578.

[15] Jiménez, S., Domingo, A., and Brazeiro, A. 2009. Seabird bycatch in the Southwest Atlantic: interaction with the Uruguayan pelagic longline fishery. Polar Biology, 32: 187-196.

[16] Orphanides, C.D. 2010. Protected species bycatch estimating approaches: estimating harbor porpoise bycatch in U.S. northwestern Atlantic gillnet fisheries. Journal of the Northwest Atlantic Fishery Science, 42: 55-76.

[17] Brodziak, J., and Walsh, W.A. 2013. Model selection and multimodel inference for standardizing catch rates of bycatch species: a case study of oceanic whitetip shark in the Hawaiibased longline fishery. Canadian Journal of Fisheries and Aquatic Sciences, 70(12): 1723-1740.

[18] Bjorge, A., Skern-Mauritzen, M., and Rossman, M.C. 2013. Estimated bycatch of harbour porpoise (Phocoena phocoena) in two coastal gillnet fisheries in Norway, 2006-2008. Mitigation and implications for conservation. Biological Conservation, 161: 164-173.

[19] Latimer, A. M., Wu, S., Gelfand, A. E. and Silander, J. A. 2006. Building statistical models to analyze species distributions. Ecological applications, 16(1): 33-50.

[20] Dormann, C., M McPherson, J., B Araújo, M., Bivand, R., Bolliger, J., Carl, G., Davies, R.G., Hirzel, A., Jetz, W., Kissling, D., Kühn, I., Ohlemüller, R., Peres-Neto, P.R., Reineking, B., 
Schröder, B., Schurr, F.M. and Wilson, R. 2007. Methods to account for spatial autocorrelation in the analysis of species distributional data: a review. Ecography, 30(5): 609-628.

[21] Clark, J.S., Carpenter, S.R., Barber, M., Collins, S., Dobson, A., Foley, J.A., Lodge, D.M., Pascual, M., Pielke, R., Pizer, W., Pringle, C., Reid, W.V., Rose, K.A., Sala, O., Schlesinger, W.H., Wall, D.H., and Wear, D. 2001. Ecological forecasts: an emerging imperative. Science, 293(5530): 657-660.

[22] Paradinas, I., Pennino, M. G., López-Quílez, A., Marın, M., Bellido, J. M. and Conesa, D. 2018. Modelling spatially sampled proportion processes. REVSTAT, Statistical Journal, 16(1): 7186.

[23] Christensen, V. and Walters, C. 2004. Ecopath with Ecosim: methods, capabilities and limitations. Ecological Modelling, 72: 109-139.

[24] Walters, C., Pauly, D. and Christensen, V. 1999. Ecospace: prediction of mesoscale spatial patterns in trophic relationships of exploited ecosystems, with emphasis on the impacts of marine protected areas. Ecosystems, 2: 539-554.

[25] Walters, C., Christensen, V., Walters, W. and Rose, K. 2010. Representation of multistanza life histories in Ecospace models for spatial organization of ecosystem trophic interaction patterns. Bulletin of Marine Science, 86: 439-459.

[26] Christensen, V., Guenette, S., Heymans, J.J., Walters, C., Watson, R., Zeller, D. and Pauly, D. 2003. Hundred-year decline of North Atlantic predatory fishes. Fish and Fisheries, 4: 1-24.

[27] Walters, C., Pauly, D., Christensen, V. and Kitchell, J.F. 2000. Representing Density Dependent Consequences of Life History Strategies in Aquatic Ecosystems: EcoSim II. Ecosystems, 3: 70-83.

[28] Christensen, V., Ferdaña, Z. and Steenbeek, J. 2009. Spatial optimization of protected area placement incorporating ecological, social and economical criteria. Ecological Modelling, 220: 2583-2593.

[29] Fulton, E. 2011. Interesting times: winners, losers, and system shifts under climate change around Australia. ICES Journal of Marine Science, 68: 1329-1342.

[30] Steenbeek, J., Coll, M., Gurney, L., Melin, F., Hoepffner, N., Buszowski, J. and Christensen, V. 2013. Bridging the gap between ecosystem modeling tools and geographic information systems: Driving a food web model with external spatial-temporal data. Ecological Modelling, 263: 139151.

[31] Coll, M., Bundy, A. and Shannon, L.J. 2008. Ecosystem Modelling Using the Ecopath with Ecosim Approach, in: Megrey, B., Moksness, E. (eds.), Computers in Fisheries Research, Second edition Springer, pp. 225-291.

[32] Christensen, V., Coll, M., Steenbeek, J., Buszowski, J., Chagaris, D. and Walters, C.J. 2014. Representing variable habitat quality in a spatial food web model. Ecosystems, 17: 1397-1412.

[33] Coll, M., Steenbeek, J., Sole, J., Palomera, I. and Christensen, V. 2016. Modelling the cumulative spatial-temporal effects of environmental factors and fishing in a NW Mediterranean marine ecosystem. Ecological Modelling, 331: 100-114.

[34] Lewis, K., de Mutsert, K., Steenbeek, J., Peele, H., Cowan, J. and Buszowski, J. 2016. Employing ecosystem models and geographic information systems (GIS) to investigate the response of changing marsh edge on historical biomass of estuarine nekton in Barataria Bay, Louisiana, USA. Ecological Modelling, 331: 129-141.

[35] de Mutsert, K., Lewis, K., Milroy, S., Buszowski, J. and Steenbeek, J. 2017. Using ecosystem modeling to evaluate trade-offs in coastal management: Effects of large-scale river diversions on fish and fisheries. Ecological Modelling, 360: 14-26.

[36] Coll, M., Pennino, M.G., Steenbeek, J., Sole, J. and Bellido, J.M. Predicting marine species distributions: complementarity of food web and Bayesian hierarchical modelling approaches. Ecological Modelling, 405: 86-101.

[37] Bosc, E., Bricaud, A. and Antoine, D. 2004. Seasonal and interannual variability in algal biomass and primary production in the Mediterranean Sea, as derived from 4 years of SeaWiFS 
observations. Global Biogeochemical Cycles, 18(1).

[38] Estrada, M. 1996. Primary production in the northwestern Mediterranean. Scientia Marina, 60: $55-64$.

[39] Maynou, F., Lleonart, J. and Cartes, J.E. 2003. Seasonal and spatial variability of hake (Merluccius merluccius L.) recruitment in the NW Mediterranean. Fisheries Research, 60: 65-78. [40] Palomera, I., Olivar, M.P., Salat, J., Sabates, A., Coll, M., Garcia, A. and Morales-Nin, B. 2007. Small pelagic fish in the NW Mediterranean Sea: An ecological review. Progress in Oceanography, 74: 377-396.

[41] Coll, M., Steenbeek, J., Ben Rais Lasram, F., Mouillot, D. and Cury, P. 2015. "Low hanging fruits" for conservation of marine vertebrate species at risk in the Mediterranean Sea. Global Ecology and Biogeography, 24: 226-239.

[42] EC Council Regulation (EC) No 199/2008 of 25 February 2008 concerning the establishment of a Community framework for the collection, management and use of data in the fisheries sector and support for scientific advice regarding the Common Fisheries Policy

[43] Shchepetkin, A. and McWilliams, J. 2005. The Regional Ocean Modeling System (ROMS): A split-explicit, free-surface, topography-following coordinates ocean model. Ocean Modelling, 9: 347-404.

[44] Fennel, K., Wilkin, J., Levin, J., Moisan, J., O’Reilly, J. and Haidvogel, D. 2006. Nitrogen cycling in the Middle Atlantic Bight: Results from a three-dimensional model and implications for the North Atlantic nitrogen budget. Global Biogeochemical Cicles, 20: GB3007.

[45] Macias, D., Catalan, I.A., Solé, J., Morales Nin, B. and Ruiz, J. 2011. Atmospheric-induced variability of hydrological and biogeochemical signatures in the NW Alboran Sea. Consequences for the spawning and nursery habitats of European anchovy. Deep Sea Research I, 58: 1175-1188. [46] Adani, M., Dobricic, S. and Pinardi, N. 2011. Quality assessment of a 1985-2007 Mediterranean Sea reanalysis. Journal of Atmospheric and Oceanic Technology, 28: 569-589.

[47] Coll, M., Pennino, M. G., Steenbeek, J., Sole, J., and Bellido, J. M. 2019. Predicting marine species distributions: Complementarity of food-web and Bayesian hierarchical modelling approaches. Ecological Modelling, 405: 86-101.

[48] Hijmans, R. J., van Etten, J., Cheng, J., Mattiuzzi, M., Sumner, M., Greenberg, J. A. and Perpinan Lamigueiro, O., et al. 2016. Package 'raster'. R package.

[49] R Core Team, 2017. R: A language and environment for statistical computing [Internet]. Vienna, Austria, 2017.

[50] Fox, J. and Weisberg, S., 2011. An R Companion to Applied Regression, Second Edition. Thousand Oaks: Sage.

[51] Zuur, A.F., Ieno, E.N. and Elphick, C.S., 2010. A protocol for data exploration to avoid common statistical problems. Methods in Ecology and Evolution 1: 3-14.

[52] Rue, H., Martino, S. and Chopin, N. 2009. Approximate Bayesian inference for latent Gaussian models by using integrated nested Laplace approximations Journal of the Royal Statistical Society: Series B, 71(2): 319-392.

[53] Lindgren, F. and Rue, H. 2015. Bayesian spatial modelling with R-INLA. Journal of Statistical Software, 63(19): 1-25.

[54] Muñoz, F., Pennino, M.G., Conesa, D., López-Quílez, A. and Bellido, J.M. 2013. Estimation and prediction of the spatial occurrence of fish species using Bayesian latent Gaussian models. Stochastic Environmental Research and Risk Assessment, 27: 1171-1180.

[55] Martínez-Minaya, J., Cameletti, M., Conesa, D. and Pennino, M. G. 2018. Species distribution modeling: a statistical review with focus in spatio-temporal issues. Stochastic Environmental Research and Risk Assessment, 1-18.

[56] Watanabe, S. 2010. Asymptotic equivalence of Bayes cross validation and widely applicable information criterion in singular learning theory. Journal of Machine Learning Research, 11: 35713594. 
665

666

667

668

669

670

671

672

673

674

675

676

677

678

679

680

681

682

683

684

685

686

687

688

689

690

691

692

693

694

695

696

697

698

699

700

701

702

703

704

705

706

707

708

709

710

711

712

713

[57] Roos, M. and Held, L. 2011. Sensitivity analysis in Bayesian generalized linear mixed models for binary data. Bayesian Analysis, 6: 259-278.

[58] Coll, M., Bahamon, N., Sardà, F., Palomera, I., Tudela, S. and Suuronen, P. 2008. Improved trawl selectivity: effects on the ecosystem in the South Catalan Sea (NW Mediterranean). Marine Ecology Progress Series, 355: 131-147.

[59] Heymans, J.J., Coll, M., Link, J.S., Mackinson, S., Steenbeek, J. and Christensen, V. 2016. Best practice in Ecopath with Ecosim food-web models for ecosystem-based management. Ecological Modelling, 331: 173-184.

[60] Christensen, V., Walters, C., Pauly, D. and Forrest, R., 2008. Ecopath With Ecosim Version 6. User Guide - November 2008. Lenfest Ocean Futures Project 2008. 235 pp.

[61] Ahrens, R. N., Walters, C. J., and Christensen, V. 2012. Foraging arena theory. Fish and fisheries, 13(1): 41-59.

[62] Coll, M., Carreras, M., Cornax, M.J., Massutí, E., Morote, E., Pastor, X., Quetglas, T., Sáez, R., Silva, L., Sobrino, I., Torres, M.A., Tudela, S., Harper, S., Zeller, D. and Pauly, D. 2014. Closer to reality: reconstructing total removals in mixed fisheries from Southern Europe. Fisheries Research, 154: 179-194.

[63] Coll, M. and Steenbeek, J. 2017. Standardized ecological indicators to assess aquatic food webs: the ECOIND software plug-in for Ecopath with Ecosim models. Environmental Modelling and Software, 89: 120-130.

[64] Coll, M., Navarro, J. and Palomera, I. 2013b. Ecological role of the endemic Starry ray Raja asterias in the NW Mediterranean Sea and management options for its conservation. Biological Conservation, 157: 108-120.

[65] Coll, M., Navarro, J., Olson, R. J. and Christensen, V. 2013. Assessing the trophic position and ecological role of squids in marine ecosystems by means of food-web models. Deep Sea Research Part II: Topical Studies in Oceanography, 95: 21-36.

[66] Coll, M., Palomera, I., Tudela, S. and Sardà, F. 2006. Trophic flows, ecosystem structure and fishing impacts in the South Catalan Sea, Northwestern Mediterranean. Journal of Marine Systems, 59(1-2): 63-96.

[67] Coll, M. and Steenbeek, J. 2017. Standardized ecological indicators to assess aquatic food webs: The ECOIND software plug-in for Ecopath with Ecosim models. Environmental modelling \& software, 89: 120-130.

[68] Heath, M.R., Cook, R.M., Cameron, A.I., Morris, D.J., Speirs, Douglas C., 2014. Cascading ecological effects of eliminating fishery discards. Nature Communications, 5, Article number: 3893 (2014), http://dx.doi.org/10.1038/ncomms4893.

[69] Machias, A., Vassilopoulou, V., Vatsos, D., Bekas, P., Kallianiotis, A., Papaconstantinou and C., Tsimenides, N. 2001. Bottom trawl discards in the northeastern Mediterranean Sea. Fisheries Research, 53(2): 181-195.

[70] Tsagarakis, K., Machias, A., Giannoulaki, M., Somarakis, S. and Karakassis, I. 2008. Seasonal and temporal trends in metrics of fish community for otter-trawl discards in a Mediterranean ecosystem. ICES Journal of Marine Science, 65(4): 539-550.

[71] Sánchez, P., Demestre, M. and Martín, P. 2004. Characterisation of the discards generated by bottom trawling in the northwestern Mediterranean. Fisheries Research, 67: 71-80.

[72] Kelleher, K. 2005. Discards in the World's Marine Fisheries: An Update, vol. 470. FAO.

[73] Santojanni, A., Cingolani, N., Arneri, E., Kirkwood, G., Belardinelli, A., Giannetti, G., Colella, S., Donato, F. and Barry, C. 2005. Stock assessment of sardine (Sardina pilchardus,Walb.) in the Adriatic Sea with an estimate of discards. Scientia Marina, 69(4): 603617.

[74] Pennino, M. G., Muñoz, F., Conesa, D., López-Quílez, A., and Bellido, J. M. 2013. Modeling sensitive elasmobranch habitats. Journal of Sea Research, 83: 209-218.. 
[75] Abella, A., Fiorentino, F., Mannini, A. and Orsi Relini, R. 2008. Exploring relationships between recruitment of European hake (Merluccius merluccius 1. 1758) and environmental factors in the Ligurian Sea and the Strait of Sicily (Central Mediterranean). Journal of Marine Systems, 71: 279-293.

[76] Vilas-González, D., Pennino, M.G., Bellido, J.M., Navarro, J., Palomera, I. and Coll, M. Submitted. Seasonality of spatial patterns of abundance, biomass and biodiversity in a demersal community from the NW Mediterranean Sea. ICES Journal of Marine Science.

[77] Lloret-Lloret E, Grazia Pennino M, Vilas D, Bellido JM, Navarro J, Coll M (In preparation) Ecological drivers and seasonal change of commercial species distributions of the NW Mediterranean Sea. Marine Ecology Progress Series.

[78] Milisenda, G., Vitale, S., Massi, D., Enea, M., Gancitano, V., Giusto, G. B., badalucco, C., Gristina, M., Garofalo, G. and Fiorentino, F. 2017. Spatio-temporal composition of discard associated with the deep water rose shrimp fisheries (Parapenaeus longirostris, Lucas 1846) in the south-central Mediterranean Sea. Mediterranean Marine Science, 18: 53-63.

[79] Malak, A., Livingstone, D., Pollard, S.R., Polidoro, B.A., Cuttelod, A., Bariche, M., Bilecenoglu, M., Carpenter, K.E., Collette, B.B., Francour, P., Goren, M., Kara, M.H., Massutí, E., Papaconstantinou, C. and Tunesi, L. 2011. Overview of the Conservation Status of the Marine Fishes of the Mediterranean Sea. IUCN. vii + 61pp., Gland, Switzerland and Malaga, Spain.

[80] FAO, 2016. The State of Mediterranean and Black Sea Fisheries, Rome 152 pp.

[81] Fernandes, P.G., Ralph, G.M., Nieto, A., Criado, M.G., Vasilakopoulos, P., Maravelias, C.D., Cook, R.M., Pollom, R.A., Kovačić, M. and Pollard, D. 2017. Coherent assessments of Europe's marine fishes show regional divergence and megafauna loss. Nature Ecology \& Evolution 1, 0170. [82] STECF, 2016. Mediterranean assessments part 2 (STECF-16-08). Publications Office of the European Union, Luxembourg, EUR 27758 EN, JRC 101548, 483 pp.

[83] Celić, Igor, et al. Ecological and economic effects of the landing obligation evaluated using a quantitative ecosystem approach: a Mediterranean case study. ICES Journal of Marine Science (2018). 
754 Appendix 1: List of the regulated species in the Mediterranean Sea as defined in Annex III to 755 Regulation (EC) No 1967/2006 that shall be brought and retained on board the fishing vessels, 756 recorded, and landed, when the landing obligation will be implemented. The length (cm) refers to 757 the Minimum Landing Size. Acronyms are: $T L=$ total length and $C L=$ carapace length.

758

\begin{tabular}{|l|l|}
\hline Species & Length $(\mathrm{cm})$ \\
\hline Dicentrarchus labrax & 25 \\
\hline Diplodus annularis & 12 \\
\hline Diplodus puntazzo & 18 \\
\hline Diplodus sargo & 15 \\
\hline Diplodus vulgaris & 15 \\
\hline Engraulis encrasicolus & 9 \\
\hline Epinephelus spp. & 45 \\
\hline Lithognathus mormyrus & 20 \\
\hline Merluccius merluccius & 20 \\
\hline Mullus spp. & 11 \\
\hline Pagellus acarne & 12 \\
\hline Pagellus bogaraveo & 33 \\
\hline Pagellus erythrinus & 15 \\
\hline Pagrus pagrus & 18 \\
\hline Polyprion americanus & 45 \\
\hline Sardina pilchardus & 11 \\
\hline Scomber spp. & 18 \\
\hline Solea vulgaris & 20 \\
\hline Sparus aurata & 20 \\
\hline Trachurus spp. & 15 \\
\hline Homarus gammarus & $30 T L, 10,5$ CL \\
\hline Nephrops norvegicus & $7 T L, 2$ CL \\
\hline Palinuridae & $9 C L$ \\
\hline Parapenaeus longirostris & $2 C L$ \\
\hline Pecten jacobeus & 10 \\
\hline Venerupis spp. & 2.5 \\
\hline & \\
\hline
\end{tabular}

